\title{
Raspberry Leaf Herbal Extract Significantly Reduces Pain and Inflammation in Oral Lichen Planus Patients - A Case Series Analysis
}

\author{
E. Russell Vickers ${ }^{1, *}$, Karen L. Woodcock ${ }^{2}$ \\ ${ }^{1}$ Sydney Oral \& Maxillofacial Surgery, Australia \\ ${ }^{2}$ GTW Dental Group, Australia
}

Copyright (C) 2015 by authors, all rights reserved. Authors agree that this article remains permanently open access under the terms of the Creative Commons Attribution License 4.0 International License

\begin{abstract}
Oral lichen planus is a frequently occurring chronic mucocutaneous inflammatory disease characterized by erosion and ulceration. The incidence is $1.7 \%$ of the population and typically presents in the $60+$ yrs age group. Current standard treatment uses topical steroids. This prospective case series analysis assessed the potential of the herb raspberry leaf (rubus idaeus) that is used traditionally by herbalists for symptomatic relief of oral ulcerative lesions. The active compounds are the small molecule flavonoids quercetin and kaempferol with demonstrated antioxidant, anticancer and chronic anti-inflammatory properties. Ten adult female subjects (mean age 69.3 yrs, SD 6.4) consented to participate in the herbal trial for 6 months. A standardized daily oral dose of $10 \mathrm{ml}(5 \mathrm{ml} \mathrm{BD})$ of professional grade high potency liquid extract (LE 1:1) was used. Results showed a significant reduction in pain intensity $(p=0.03)$ and clinical features of reticulation, erosion and ulceration $(p=0.007)$ at the end of the trial. No adverse clinical or systemic effects were observed in the subjects. In addition, dermal symptoms were improved. This study showed that raspberry leaf herbal extract is both a safe and efficacious treatment for oral lichen planus and potentially its dermal variant.
\end{abstract}

Keywords Lichen Planus, Oral, Plants, Medicinal, Quercetin, Kaempferols, Lichen Planus

\section{Introduction}

Oral lichen planus (OLP) is a frequently occurring chronic mucocutaneous inflammatory disease. The incidence is $1.7 \%$ of the population. It typically presents in the $60+$ yrs age group and females are predisposed to this condition compared with males 2.5-3:1. Once acquired it appears to be a life long condition that can greatly affect quality of life as extensive areas of the oral mucosa can be ulcerated. This can restrict the nutritional intake triggering secondary medical problems. In addition, patients often report a decreased quality of life due to pain on eating and talking for social occasions. Approximately two thirds of OLP patients report oral discomfort. Most cases of symptomatic OLP are associated with atrophic (erythematous) or erosive (ulcerative) lesions. Symptoms vary from mucosal sensitivity to continuous debilitating pain [1]. OLP is an autoimmune disease with occasional lesions on the skin and nail beds causing deformity. CD8 $+\mathrm{T}$ lymphocytes, and chemical mediators such as the cytokine tumour necrosis factor alpha are implicated in histopathogenesis. Similar conditions of the oral cavity both clinically and histopathologically include lichenoid contact lesions, lichenoid drug reactions, and lichenoid lesions of graft-versus-host disease [2,3]. Patients with OLP may progress to oral cancer [4] although the incidence of malignant transformation is low at $2.45 \%$ over 6.8 years (average $0.36 \%$ per year) [5]. Causation of the disease in the large majority of patients is idiopathic. For some patients with a similar oral autoimmune condition (lichenoid drug reaction) the symptoms have been resolved by the exclusion of gold therapy, antihypertensive medication, and removal of potential contact allergens such as mercury rich amalgam restorations. Initial diagnosis is made by clinical symptom presentation and confirmed by histopathology using direct immunofluorescence for positive staining of fibrinogen, immunoglobulins and complement.

A recent systematic review of treatments reported that topical betamethasone and the potent topical steroids clobetasol-17-propionate and fluocinonide are effective in the treatment of OLP when compared with placebo [6]. A concern often raised by dentists and doctors is the overuse of the topical steroid by patients. The oral mucosa has rapid absorption of drugs and is further increased in OLP with patches of erosion and ulceration. The constant daily pain and oral discomfort from simple daily functional activities such as of talking and eating can result in the overuse of the topical steroid creams causing secondary oral candidiasis in $11-47 \%$ of patients [7]. Other OLP treatment options include 
calcineurin inhibitors and topical retinoids. Calcineurin inhibitors reduce inflammation, however a common side effect is burning and itching for several days with less common side effects that include acne, headache, increased sensitivity of the skin to hot and cold temperatures, and flu-like symptoms. Topical calcineurin inhibitors are relatively new, and long-term side effects are not fully known. The U.S. Food and Drug Administration (FDA) recommends caution when prescribing or using calcineurin inhibitors as several cases of cancer have been reported from their use although conclusive evidence has not been demonstrated [8].

Two studies have investigated herbal medicine for OLP. One study used a combination of three traditional Chinese herbs (Radix astragale, Fructus lycii, Fructus ziziphi jujubae) with the synthetic immunomodulator levamisole and showed reduction in serum levels of the inflammatory cytokine marker interleukin-6. Combination therapy of herb and drug were better than levamisole alone [9]. A more recent randomized controlled trial (RCT) of the herb purslane to treat OLP reported that $17 / 20$ patients incurred partial to complete pain relief [10].

\section{Raspberry Leaf extract}

Raspberry (rubus idaeus) is a shrub 1-2 metres high and grows in Europe, Australia and New Zealand. It has a long history of cultivation for the raspberry fruit used in the human diet. Raspberry leaf has also been used empirically for centuries by western herbalists for the treatment of a number of oral health conditions including mucosal inflammation such as stomatitis and 'bleeding gums'. Medical applications of the herb include treating dysmenorrhea and to facilitate childbirth [11]. The active constituents identified in the leaf are mainly tannins and the two flavonoids kaempferol and quercetin. Raspberry leaf extract is an approved Australian herb and is described and referenced in the major textbook used by Australian herbalists and naturopaths [12]. This reference book states that the herbal extract has no known medical contraindications, no known drug interactions, no known side effects and is considered safe for use in pregnancy and breastfeeding. However, an extensive peer reviewed pharmacological assessment of the safety of RLE for female patients with precancerous or cancerous conditions such as breast cancer, uterine cancer, ovarian cancer, endometriosis or uterine fibroids has not been reported in the literature. The purpose of this investigation was to report on preliminary efficacy and safety of raspberry leaf extract in patients with OLP.

\section{Materials and Methods}

\subsection{Subjects}

Ten subjects, all consenting adults were invited to participate in this study. The study was conducted in compliance with the Declaration of Helsinki, International
Conference on Harmonization Good Clinical Practice guidelines. All subjects were current patients of the authors at their respective private health clinics and had been previously diagnosed with OLP by biopsy and histopathology by an oral medicine specialist. Subjects reported a history of sporadic use of topical steroids and were under regular review of their OLP by KW/ERV. Pain scores and clinical photographic records are standard clinical record keeping data of the investigators in the treatment of patients. There were no changes to any of the current medication and subjects could discontinue the trial at any time.

\subsection{Data Collection}

Subjects were reviewed initially for their consent and at 3 , $6,12,19$ and 26 weeks giving six data collection points. At each time point the average pain score of the previous seven days was recorded. The pain intensity scale was the $0-10$ numerical rating scale, with end anchors $0=$ no pain, $10=$ worst pain imaginable. High resolution clinical photography was taken of the oral cavity at each time point and was assessed by the validated method for measuring OLP as described by Park et al [13] (see Fig.1). This method divides the mucosal surfaces of the oral cavity into distinct anatomical regions and is combined with a weighted numerical scoring system of severity for reticulation/keratosis, erosions and erythema, and ulceration (REU) of lesions. The method can assess improvement on several indices to better understand the nature of OLP and potential treatment effects. The photographic equipment was a Canon EOS 650D body with $100 \mathrm{~mm}$ Macro lens and ring flash (MR-14 EX TTL Macro Ring Lite). Images were captured at $1 / 125 \mathrm{sec}$ and $\mathrm{f} 25$.

\subsection{Materials}

Raspberry leaf extract was purchased from Herbal Extracts of Australia Pty Ltd (Sydney, Australia). The company specialises in high quality extracts using a typical 1 $\mathrm{kg}$ plant material in 1 litre solvent (water/ 30\% alcohol) technique to yield a liquid (fluid) 1:1 labelled extract. The company conducts quality assurance for the presence of the key actives and any plant contaminants and is performed by high performance liquid chromatography. The dose of the herb was to take $5 \mathrm{ml}$ of 1:1 liquid extract in a glass of water at breakfast and dinner. Where the subject wished to avoid consuming alcohol, the instruction was to add the liquid extract to a cup of boiling water and then allow it to cool down to room temperature. The technique is to evaporate off the alcohol (boiling point 80 degrees Celsius). The liquid extract was provided to subjects at the manufacturer's cost price.

\subsection{Statistical Methods}

Student's $t$ test was performed for pain intensity and REU raw scores. Within subjects ANOVA was performed for weighted REU lesions with a level of significance at $p<0.05$. Pearson's R was used for correlation between variables. 


\section{REU Score Sheet}

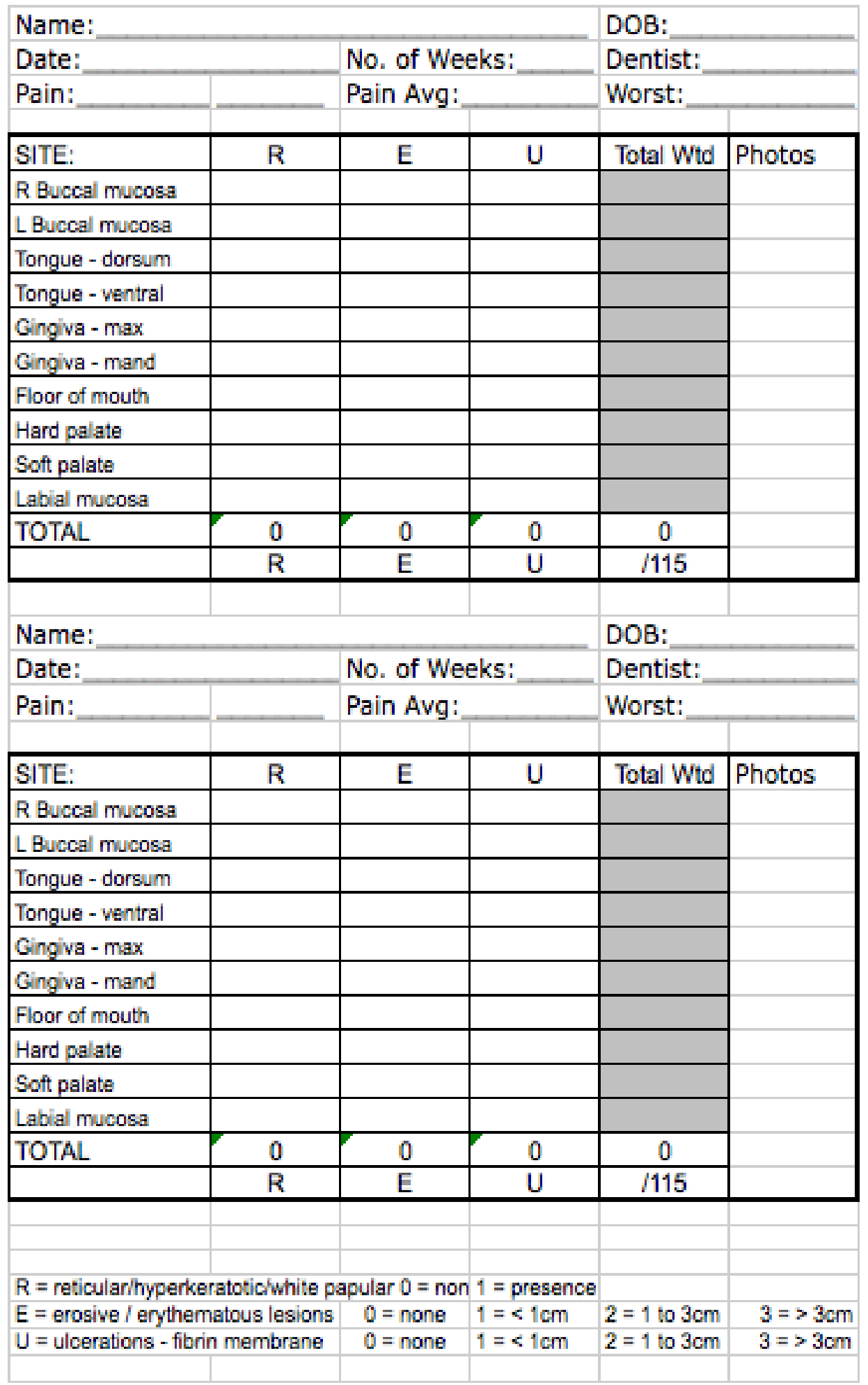

Figure 1. REU score sheet template based on presence and severity of lesions. Severity graded 0-3 based on area of lesion and given a raw score, then adjusted with a weighted index to yield a final total score (Park et al. 2012). On the REU score chart grade $<1 \mathrm{~cm}\left(=\operatorname{area}<1 \mathrm{~cm}^{2}\right) ; 2\left(=\operatorname{area} 1-3 \mathrm{~cm}{ }^{2} ; 3\right.$ $\left(=\right.$ area $\left.>3 \mathrm{~cm}^{2}\right)$. Pain intensity scored $0-10(0=$ no pain, $10=$ worst pain imaginable $)$ averaged over previous 7 days. 


\section{Results}

Subjects were all females, age range 62-79 yrs (mean 69.3 yrs, SD 6.4). The duration of the condition ranged from 2-16 yrs (mean 7.4 yrs, SD 5). A total of 57/60 clinical data points were recorded $(7$ subjects with 6 clinic reviews, 3 subjects with 5 reviews) (see Table 1). No adverse clinical or systemic effects were observed in the subjects. The pain intensity before the trial ranged from 0-8 (mean 1.9, SD 2.6) and at 26 weeks there was a significant reduction in pain intensity with all subjects reporting pain at 0 (mean $0, \mathrm{SD} 0)$, ( $\mathrm{p}=0.03$, $\mathrm{t}$ test), see Fig.2(a). The REU weighted scores showed a significant reduction in clinical pathology (initial score: mean $23.7 \pm 8.2$, range 11.5-39; at 26 weeks: mean $13.2 \pm 3.8$, range 6.5-18, $\mathrm{p}=0.007$, ANOVA, d.f. $=4, \mathrm{~F}=$ 4.33), see Fig.2(b). The correlation between improvement of the REU weighted score and reduced pain intensity during the trial was $\mathrm{R}=0.82$ (Pearson's product coefficient).

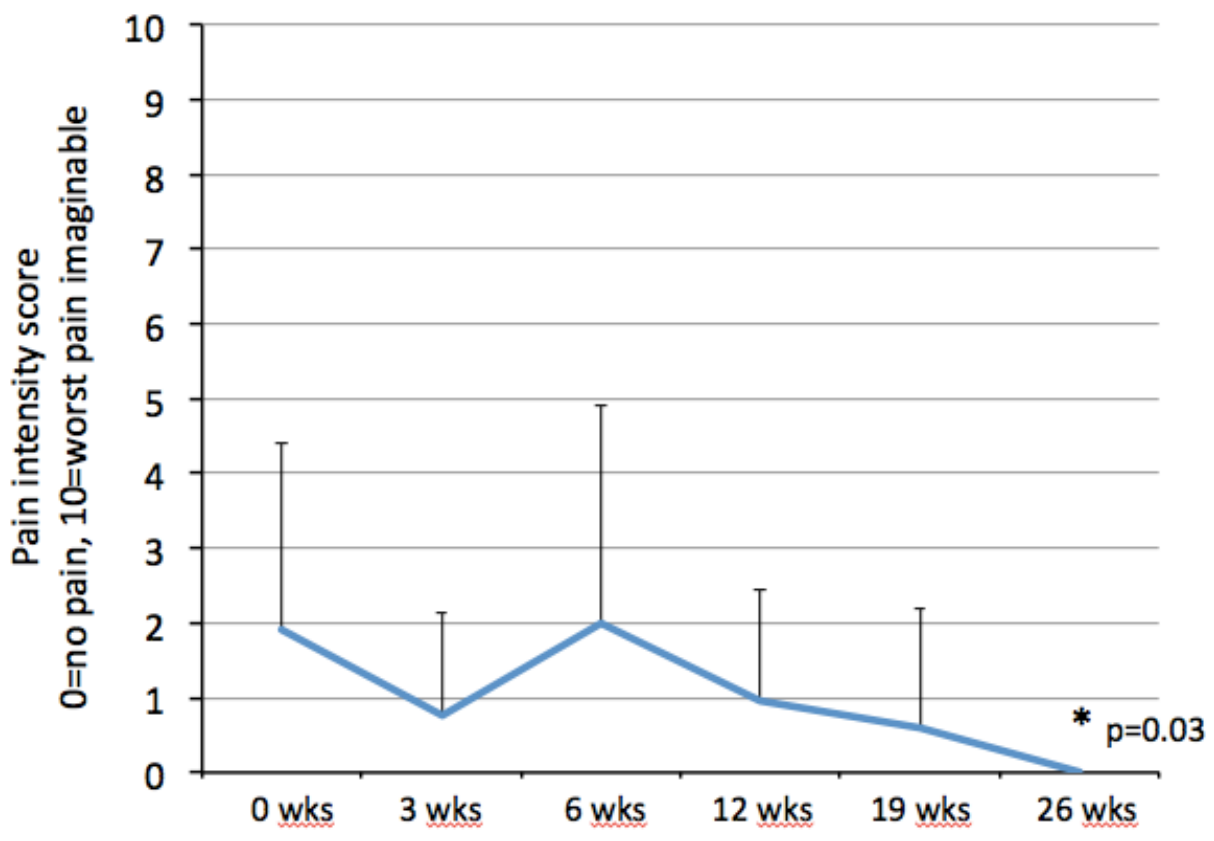

Figure 2(a). Mean (SD) scores for pain intensity throughout the trial from before treatment ( 0 wks) to completion of trial at 26 weeks. Significant reduction in mean pain intensity from 0 wks to 26 wks $(p=0.03$, t-test).

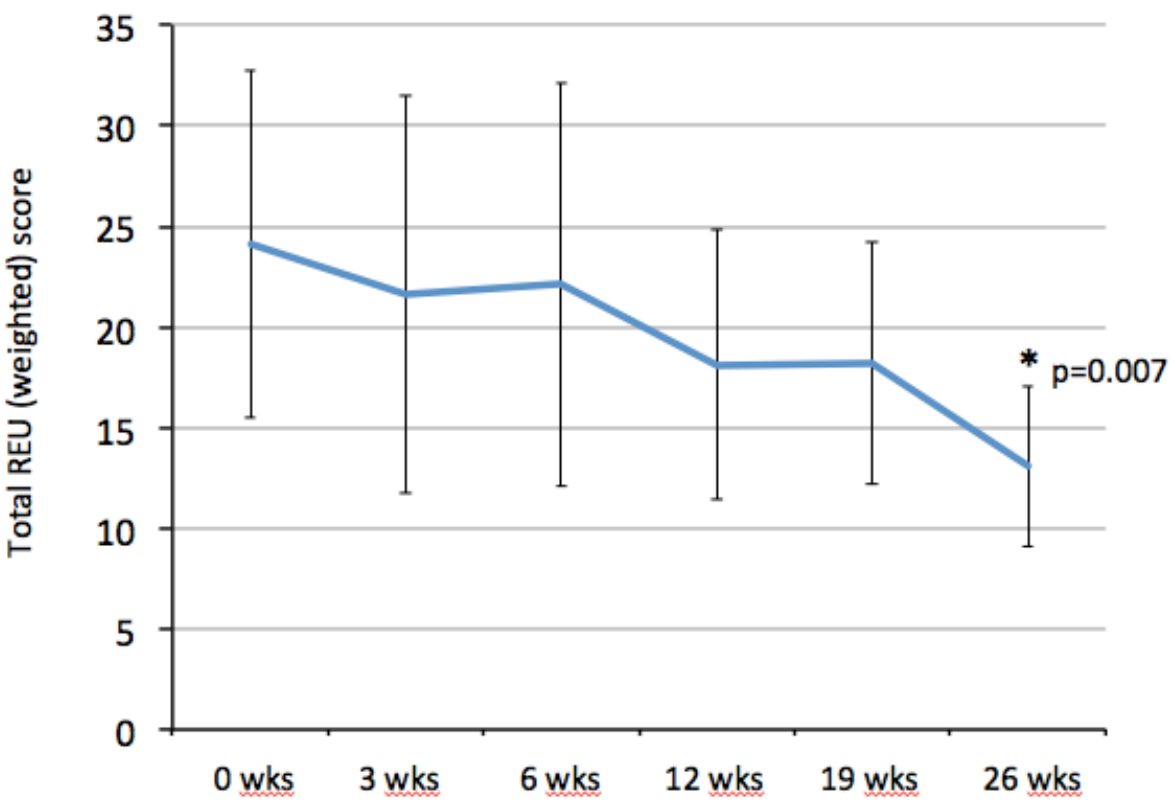

Figure 2(b). Mean (SD) scores of REU weighted indices throughout the trial from before treatment ( 0 wks) to completion of trial at 26 weeks. Significant reduction in mean REU from 0 wks to 26 wks ( $p=0.007$, ANOVA). 
Table 1. Individual data of each subject for demographics, medication, pain intensity scores and REU scores. For time point reviews $57 / 60$ visits were completed. There is missing data for subjects no. 6 \& 10 at 3 wks, subject no. 8 at 26 wks where subjects were unable to attend.

\begin{tabular}{|c|c|c|c|c|c|c|c|c|}
\hline $\begin{array}{l}\text { Subject no. } \\
\text { Gender } \\
\text { Age } \\
\text { Duration }\end{array}$ & Medication & $\begin{array}{l}\text { Time } \\
\text { point }\end{array}$ & $\begin{array}{c}\text { Pain } \\
\text { intensity } \\
0-10\end{array}$ & $\begin{array}{l}\text { Reticulation } \\
\text { (raw score) }\end{array}$ & $\begin{array}{c}\text { Erosions } \\
\text { (raw score) }\end{array}$ & $\begin{array}{l}\text { Ulceration } \\
\text { (raw score) }\end{array}$ & $\begin{array}{c}\text { REU Total } \\
\text { (raw } \\
\text { Score) }\end{array}$ & $\begin{array}{c}\text { REU Total } \\
\text { (weighted } \\
\text { Score) }\end{array}$ \\
\hline 1 & risedronate & $0 \mathrm{wks}$ & 3 & 6 & 14 & 6 & 26 & 39 \\
\hline female & telmisartan & 3 wks & 3 & 7 & 14 & 3 & 24 & 34 \\
\hline $79 \mathrm{yrs}$ & $\begin{array}{c}\text { polyethylene } \\
\text { glycol }\end{array}$ & $6 \mathrm{wks}$ & 8.5 & 8 & 14 & 5 & 27 & 39 \\
\hline \multirow[t]{3}{*}{$8 \mathrm{yrs}$} & \multirow[t]{3}{*}{ dexamethasone } & $12 \mathrm{wks}$ & 4 & 7 & 14 & 1 & 22 & 30 \\
\hline & & 19 wks & 0 & 6 & 10 & 1 & 17 & 23 \\
\hline & & $26 \mathrm{wks}$ & 0 & 6 & 7 & 0 & 13 & 16.5 \\
\hline \multirow{6}{*}{$\begin{array}{c}2 \\
\text { female } \\
67 \mathrm{yrs} \\
15 \mathrm{yrs}\end{array}$} & \multirow{6}{*}{$\begin{array}{l}\text { lercanidipine } \\
\text { rabeprazole } \\
\text { metformin }\end{array}$} & 0 wks & 0 & 5 & 10 & 1 & 16 & 22 \\
\hline & & $3 \mathrm{wks}$ & 0 & 5 & 10 & 0 & 15 & 20 \\
\hline & & $6 \mathrm{wks}$ & 0 & 5 & 11 & 0 & 16 & 21.5 \\
\hline & & $12 \mathrm{wks}$ & 0 & 5 & 10 & 0 & 15 & 20 \\
\hline & & 19 wks & 0 & 5 & 9 & 0 & 14 & 18.5 \\
\hline & & $26 \mathrm{wks}$ & 0 & 4 & 8 & 0 & 12 & 16 \\
\hline \multirow{6}{*}{$\begin{array}{c}3 \\
\text { female } \\
79 \text { yrs } \\
7 \text { yrs }\end{array}$} & \multirow{6}{*}{$\begin{array}{l}\text { levothyroxine } \\
\text { letrozole } \\
\text { duloxetine } \\
\text { zoledronic acid }\end{array}$} & 0 wks & 0 & 7 & 12 & 2 & 21 & 29 \\
\hline & & $3 \mathrm{wks}$ & 0 & 5 & 13 & 3 & 21 & 30.5 \\
\hline & & $6 \mathrm{wks}$ & 4 & 6 & 10 & 3 & 19 & 27 \\
\hline & & $12 \mathrm{wks}$ & 1 & 6 & 11 & 1 & 18 & 24.5 \\
\hline & & 19 wks & 0 & 6 & 8 & 2 & 16 & 22 \\
\hline & & $26 \mathrm{wks}$ & 0 & 6 & 8 & 0 & 14 & 18 \\
\hline \multirow{6}{*}{$\begin{array}{c}4 \\
\text { female } \\
70 \text { yrs } \\
16 \text { yrs }\end{array}$} & \multirow{6}{*}{$\begin{array}{l}\text { raloxifene } \\
\text { vitamin } \mathrm{D} \\
\text { betamethasone } \\
\text { glucosamine }\end{array}$} & 0 wks & 1 & 4 & 5 & 0 & 9 & 11.5 \\
\hline & & $3 \mathrm{wks}$ & 0 & 3 & 5 & 0 & 8 & 10.5 \\
\hline & & $6 \mathrm{wks}$ & 0 & 4 & 4 & 0 & 8 & 10 \\
\hline & & $12 \mathrm{wks}$ & 0 & 4 & 3 & 1 & 8 & 10.5 \\
\hline & & 19 wks & 0 & 4 & 4 & 1 & 9 & 12 \\
\hline & & $26 \mathrm{wks}$ & 0 & 4 & 3 & 0 & 7 & 8.5 \\
\hline \multirow{6}{*}{$\begin{array}{c}5 \\
\text { female } \\
65 \mathrm{yrs} \\
4 \mathrm{yrs}\end{array}$} & \multirow{6}{*}{$\begin{array}{l}\text { thyroxine } \\
\text { ramipril } \\
\text { rosuvastatin }\end{array}$} & 0 wks & 0 & 5 & 9 & 0 & 14 & 18.5 \\
\hline & & $3 \mathrm{wks}$ & 0 & 5 & 7 & 0 & 12 & 15.5 \\
\hline & & $6 \mathrm{wks}$ & 0 & 6 & 7 & 0 & 13 & 16.5 \\
\hline & & $12 \mathrm{wks}$ & 0 & 6 & 7 & 0 & 13 & 16.5 \\
\hline & & 19 wks & 0 & 5 & 7 & 0 & 12 & 15.5 \\
\hline & & $26 \mathrm{wks}$ & 0 & 5 & 6 & 0 & 11 & 14 \\
\hline \multirow{6}{*}{$\begin{array}{c}6 \\
\text { female } \\
72 \text { yrs } \\
3 \text { yrs }\end{array}$} & \multirow{6}{*}{$\begin{array}{l}\text { candesartan } \\
\text { atenolol } \\
\text { rosuvastatin }\end{array}$} & 0 wks & 1 & 5 & 13 & 0 & 18 & 24.5 \\
\hline & & $3 \mathrm{wks}$ & & & & & & \\
\hline & & $6 \mathrm{wks}$ & 2 & 6 & 11 & 1 & 18 & 24.5 \\
\hline & & $12 \mathrm{wks}$ & 3.5 & 3 & 8 & 0 & 11 & 15 \\
\hline & & 19 wks & 0 & 5 & 7 & 0 & 12 & 15.5 \\
\hline & & $26 \mathrm{wks}$ & 0 & 5 & 6 & 0 & 11 & 14 \\
\hline \multirow{6}{*}{$\begin{array}{c}7 \\
\text { female } \\
73 \mathrm{yrs} \\
8 \mathrm{yrs}\end{array}$} & \multirow{6}{*}{$\begin{array}{c}\text { fluticasone/ } \\
\text { salmeterol } \\
\text { tiotropium } \\
\text { bromide } \\
\text { ciclesonide } \\
\text { albuterol } \\
\text { budesonide } \\
\text { pantoprazole }\end{array}$} & 0 wks & 0 & 6 & 11 & 1 & 18 & 24.5 \\
\hline & & $3 \mathrm{wks}$ & 0 & 6 & 8 & 1 & 15 & 20 \\
\hline & & $6 \mathrm{wks}$ & 0 & 4 & 8 & 1 & 13 & 18 \\
\hline & & $12 \mathrm{wks}$ & 0 & 4 & 7 & 1 & 12 & 16.5 \\
\hline & & 19 wks & 0 & 6 & 8 & 1 & 15 & 20 \\
\hline & & $26 \mathrm{wks}$ & 0 & 2 & 6 & 0 & 8 & 11 \\
\hline 8 & escitalopram & 0 wks & 8 & 9 & 13 & 2 & 24 & 32.5 \\
\hline female & simvastin & 3 wks & 3 & 9 & 16 & 0 & 25 & 33 \\
\hline 64 yrs & betamethasone & 6 wks & 4.5 & 9 & 16 & 0 & 25 & 33 \\
\hline $9 \mathrm{yrs}$ & & $12 \mathrm{wks}$ & 1 & 9 & 8 & 0 & 17 & 21 \\
\hline & & $\begin{array}{l}19 \mathrm{wks} \\
26 \mathrm{wks}\end{array}$ & 1 & 9 & 13 & 0 & 22 & 28.5 \\
\hline 9 & nil & 0 wks & 1.5 & 4 & 6 & 1 & 11 & 15 \\
\hline female & & 3 wks & 0 & 3 & 4 & 0 & 7 & 9 \\
\hline $62 \mathrm{yrs}$ & & $6 \mathrm{wks}$ & 1 & 3 & 4 & 0 & 7 & 9 \\
\hline 3 yrs & & $12 \mathrm{wks}$ & 0 & 4 & 3 & 0 & 7 & 8.5 \\
\hline & & 19 wks & 0 & 3 & 4 & 0 & 7 & 9 \\
\hline & & $26 \mathrm{wks}$ & 0 & 2 & 3 & 0 & 5 & 6.5 \\
\hline 10 & nil & $0 \mathrm{wks}$ & 4.5 & 6 & 8 & 1 & 15 & 20 \\
\hline female & & 3 wks & & & & & & \\
\hline 62 yrs & & 6 wks & 0 & 4 & 6 & 0 & 10 & 13 \\
\hline $2 \mathrm{yrs}$ & & $12 \mathrm{wks}$ & 0 & 4 & 4 & 0 & 8 & 10 \\
\hline & & 19 wks & 5 & 4 & 6 & 1 & 11 & 15 \\
\hline & & $26 \mathrm{wks}$ & 0 & 4 & 7 & 0 & 11 & 14.5 \\
\hline
\end{tabular}


Raw score analysis from before the trial compared with 26 weeks showed significant improvements (t test) in reticulation/keratosis $\mathrm{p}=0.045$ (initial score range 4-9, mean 5.7, SD 1.5; at 26 weeks range $2-6$, mean 4.2 , SD 1.5), erosion $\mathrm{p}=0.003$ (initial score range $6-14$, mean 10.1, SD 3.1; at 26 weeks range 3-8, mean $6, \mathrm{SD} 2.8$ ) and ulceration $p$ $=0.03$ (initial score range $0-6$, mean 1.4, SD 1.5 ; at 26 weeks range 0 , mean $0, \mathrm{SD} 0$ ).

\section{Discussion}

\subsection{Safety of Raspberry Leaf Extract}

A review of the medical and scientific literature has reported no adverse effects of this herb. The principal active compounds of RLE are the two flavonoids quercetin and kaempferol. Both have been extensively studied as part of human dietary food intake. Quercetin is found in many foods including citrus fruits, apples, onions, berries and red wine and has multiple biological effects. A recent review concluded that circulating concentrations of quercetin from a regular diet $(<1 \mu \mathrm{M})$ did not achieve its chemopreventive and/or cardioprotective effects. Higher plasma concentrations $(>10 \mu \mathrm{M})$ by enriched foods or supplements suggest a positive association between quercetin intake and improved outcomes of inflammatory cardiovascular risk and chronic inflammatory disorders [14]. In addition, kaempferol is found in high concentrations in capers, kale, chives and broccoli. A further review reports the beneficial effects of kaempferol as an antioxidant in chronic diseases and has been shown to induce cancer cell apoptosis, yet preserve normal cell viability [15]. RLE does contain other potential therapeutic actives including several elligatannins, phenolic acids, minerals and vitamins (including $\alpha-, \delta$ - and $\gamma$-tocopherols with epithelialisation properties). The philosophy of herbalism is that the combined properties of whole plant constituents are synergistic with improved health outcomes and less side effects compared with individual purified (pharmaceutical) actives.

In this study we observed no side effects utilising a systemic supplementation of quercetin and kaempferol via the oral intake of RLE, similar to its safe empirical use in childbirth. Controlled higher dose response studies of RLE are indicated but one problematic issue with future investigations of any herbal medicine is to obtain consistency in concentrations of the active compounds. This can vary according to plant conditions including soil type, season of cultivation, rainfall patterns and species variations that may confound the data. For example, Echinacea herb that is traditionally used to treat or prevent viral colds is found and used by herbalists in three different species: E. angustifolia, E. pallida and E. purpurea. Future clinical studies on the use of RLE warrant the determination of the concentrations of quercetin and kaempferol by liquid chromatography and mass spectrometry for standardisation of doses.

The professional grade RLE used in this study contained $30 \%$ alcohol serving a dual purpose for solvent extraction of actives during the manufacturing process and as the antimicrobial preservative for shelf life of the product. A concern raised by the investigators was potential tissue change due to the twice daily intake of alcohol but no side effects were observed. Furthermore, pretesting of this amount of alcohol in a 'breath alcohol test' showed a nil result providing reassurance to subjects who were driving a motor vehicle after the herb intake. The simple method of alcohol removal using boiling water as previously mentioned further reassured the subjects and was used by one patient. RLE is also available in a powdered form in Australia and may be a suitable oral alternative if therapeutic plasma concentrations of the actives are demonstrated.

\subsection{Efficacy}

Analysis of the results showed a positive correlation between improvement of both the signs (reduced REU scores) and symptoms (reduced pain) of the disease. Most therapeutic benefit was observed in the 3-6 months period suggesting that the herbal extract needs to be maintained for long term efficacy. Extrapolation of the data indicates a future trial should be undertaken for 12 months to monitor any continued improvement on the REU scores past 6 months. This trial only evaluated a daily dosage of $10 \mathrm{ml}(5$ $\mathrm{ml} \mathrm{BD}$ ). Considering that this herb has a wide margin of safety a higher daily dose may prove more efficacious. In contrast, topical steroids, while helpful in acute episodes of widespread and painful OLE, can cause serious side effects from chronic use of these drugs. Non-compliant patients, particularly those who use topical steroids daily, can initiate further secondary local oral health problems such as candidiasis or serious medical complications such as Cushing's syndrome.

This study was continued for 6 months to negate the influence of the placebo effect in this open labelled trial. Typically, any placebo effect from an intervention for chronic pain and disease is limited to less than 3 months. It was noted that the previous trial of purslane was limited to 3 months and only analogue pain scores recorded. This extended RLE trial of 6 months with quantitative data could be considered as further evidence on the use of herbal medicines to be studied in oral health disease management. Several herbs such as tea tree, thyme and peppermint are reported to have excellent (in vitro) evidence of oral antifungal properties [16]. The utilisation of traditional medicine is still very frequent in developing countries and is gaining popularity in western society. Unfortunately there is still a paucity of published clinical herbal studies for oral health practice underpinned by the western paradigm of rigorous published evidence based medicine. Results of this RLE study measured quantifiable changes in the signs of the disease process (erosion and ulceration), in addition to the invisible symptoms of OLP (pain / discomfort). Both 
measures showed statistical significance substantiating a genuine therapeutic response of the RLE herb. We also observed the healing phase to progress from ulceration to erosion and then to reticulation / keratosis, as identified by Sugerman et al [1] that keratosis was the end-point of OLP therapy. Considering the limited options of current treatments for OLP, particularly concerning chronic overuse of topical steroids, then the RLE herb is worthy of further investigation in both an oral systemic form as administered in this trial and to assess a topical gel form applied directly to the lesions.

\subsection{Critique of Methods}

A difficulty of the REU method used in this study was determining the demarcation of contiguous lesions during analysis - what constituted the boundary in flexible mucosa, yet anatomical distinct regions as defined by Park et al [13]. For example, several lesions extended from the gingival margin through to the cheek mucosa. The method the investigators employed was identifying and maintaining designated boundaries such as the base of the vestibule, combined with dental landmarks such as tooth number, its crown height and width throughout all subjects to maintain consistency of assessment. In addition, where there was a patchwork appearance of the lesion, the total area of the patches was estimated for the area. A further difficulty was to photograph consistently the painful stretched tissue for the extra-oral 2D photograph. Greater accuracy of the extent of the lesion may be accomplished using an intraoral camera with an inbuilt graded $\mathrm{mm}$ scale. In addition, the Identafi® device used for oral cancer screening, uses multispectral fluorescence and reflectance and may more accurately map areas of erythema than using white light flash photography.

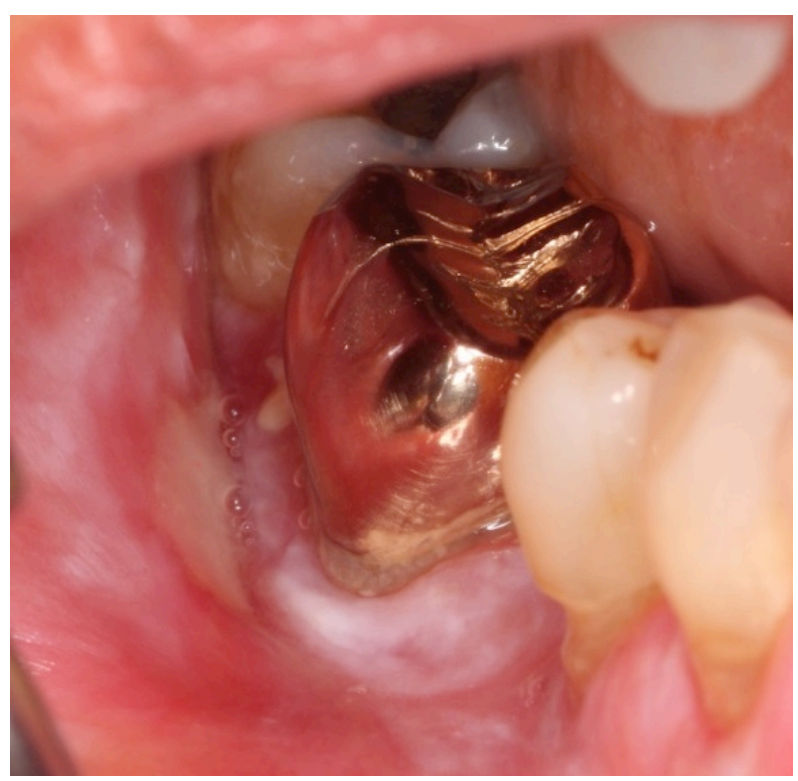

Figure 3(a)

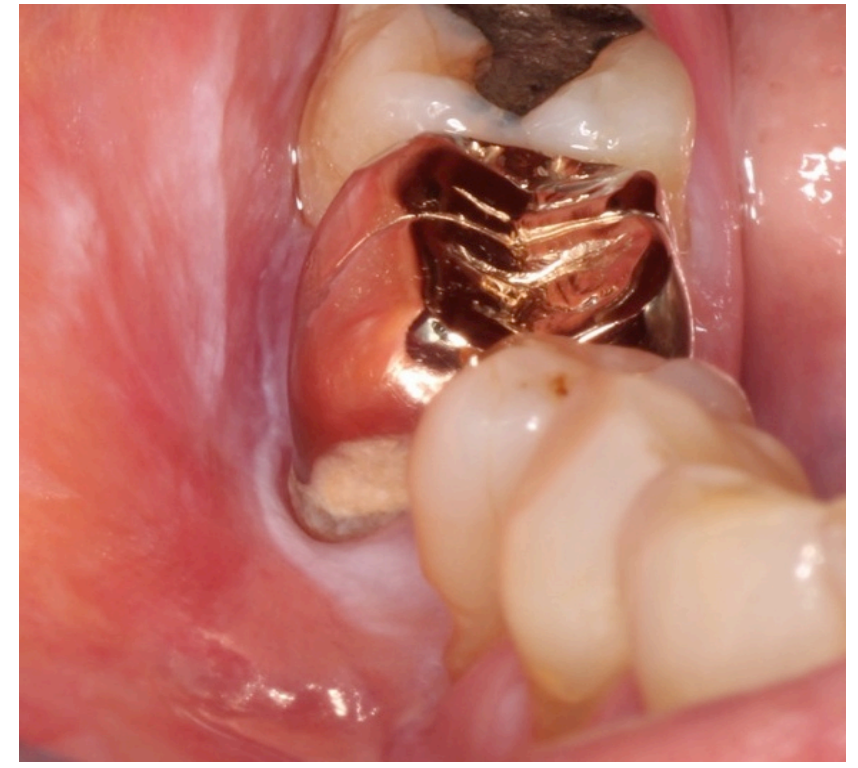

Figure 3(b)

Figures 3(a) \& 3(b). Subject 1 at 0 weeks, 3(a) shows ulceration surrounded by erythema and keratosis; 3 (b) at 26 weeks shows resolution of the ulcer, loss of erythema and reduction of keratosis.

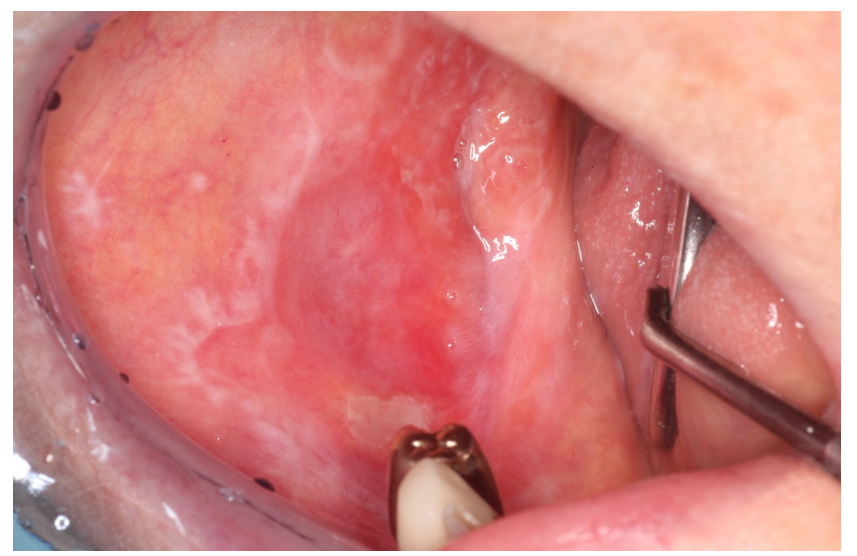

Figure 4(a)

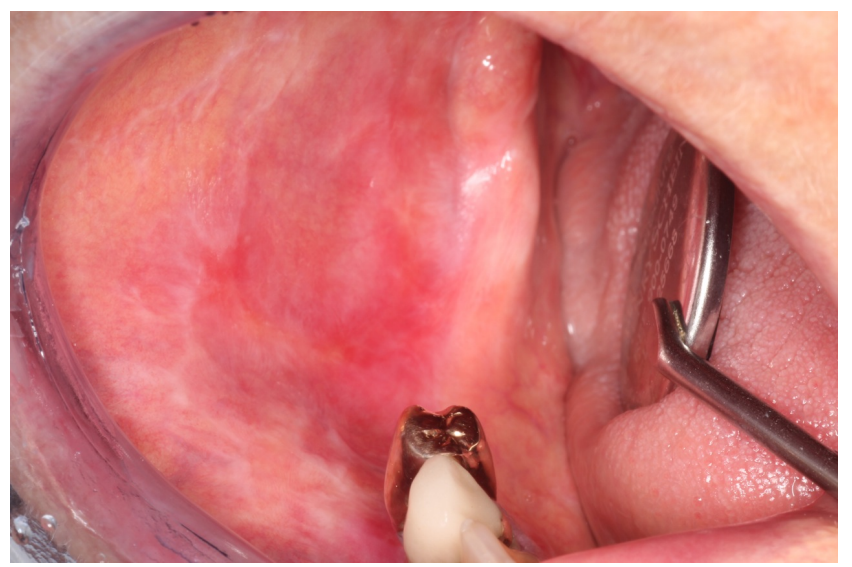

Figure 4(b)

Figures 4(a) \& 4(b). Subject 3 at 0 weeks, 4(a) shows ulceration and a wide area of erosion bordered by keratosis; 4(b) at 26 weeks shows resolution of the ulcer, improved erythema and reduction of keratosis. 


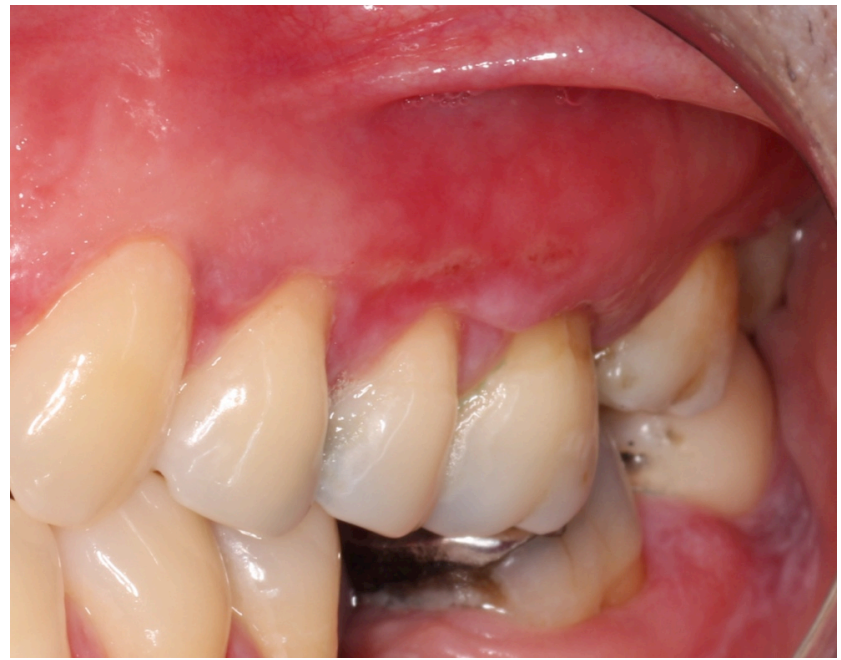

Figure 5(a)

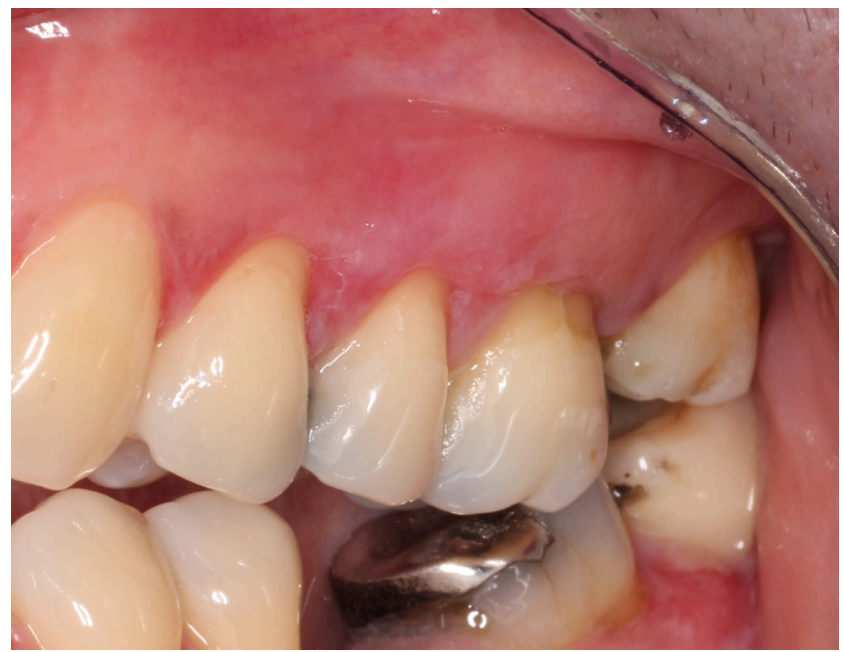

Figure 5(b)

Figures 5(a) \& 5(b). Subject 10 at 0 weeks, 5(a) shows a longitudinal ulcer surrounded by erythema; 5(b) at 26 weeks shows resolution of the ulcer and erythema.

\subsection{Further Observation}

One characteristic of the lesions identified in the study was the progression of the healing phase from ulceration to erosion, then to keratinisation. The healing phase of some lesions took several weeks and months. There was still visible redness in the OLP areas but greatly reduced at the end of the 6 month trial (see Figs. 3, 4, 5). This suggests that although the underlying pathophysiology is still present the herbal extract can provide excellent symptomatic relief of OLP. One interesting observation was subject no. 1 from the Indian subcontinent who had extensive pigmentation at the commencement of the trial termed inflammatory melanosis. By the end of the trial this had completely disappeared. Informative comments were provided by two subjects on the use of the herb for dermal lichen planus. One subject had discoloured and partially deformed nails for 6 years that completely cleared by the end of the trial. Another subject reported that while her oral lesions had improved, the vulvo-vaginal lesions (not previously disclosed to the investigators) had substantial improvement. At the end of the trial a total of $8 / 10$ subjects wished to continue RLE therapy long term. The overwhelming response from the participants was highly favorable. The subjects reported an increased quality of life by more frequently talking and eating with friends and family. Furthermore, the erosions and ulcerations had caused a restricted diet and compromised oral hygiene of toothbrushing - at trial commencement the pain intensity in two subjects increased from 0 to 8 , and 4.5 to 8 while brushing. Further long term controlled studies are warranted to determine dose response parameters of RLE considering the prevalence of OLP in the population. Moreover, undertreatment of aggressive OLP with frequent and extensive erosion and ulceration is likely to increase the risk of oral cancer, and overtreatment using steroids can result in serious medical consequences. In this preliminary study, raspberry leaf herbal extract has shown safety and efficacy for treating OLP.

\section{Conclusions}

This proof of concept study evaluated a traditional herbal medicine for the treatment of a common and debilitating oral disease with current treatment (topical steroids) having possible serious side effects if overused. This study showed that raspberry leaf herbal extract is both a safe and efficacious treatment for oral lichen planus and potentially its dermal symptoms. Follow-up dose response studies and randomised controlled trials are warranted to determine the further potential of the treatment.

\section{Competing Interests}

The authors declare they have no competing interests.

\section{Authors' Contributions}

ERV: designed the study, performed statistical analyses and wrote the manuscript, $\mathrm{KW}$ : designed the study, collected data and wrote the manuscript. All authors have read and approved the final manuscript.

\section{Acknowledgements}

The participating volunteers are gratefully acknowledged.

\section{REFERENCES}

[1] P.B. Sugerman, N.W. Savage. Oral lichen planus: Causes, diagnosis and management. Australian Dental Journal, Vol.47, 290-297, 2002. 
[2] I. Al-Hashimi, M. Schifter, P.B. Lockhart, D. Wray, M. Brennan, C.A. Migliorati, T. Axéll, A.J. Bruce, W. Carpenter, E. Eisenberg, J.B. Epstein, P. Holmstrup, M. Jontell, F. Lozada-Nur, R. Nair, B. Silverman, K. Thongprasom, M. Thornhill, S. Warnakulasuriya, I. van der Waal. Oral lichen planus and oral lichenoid lesions: diagnostic and therapeutic considerations. Oral Surgery Oral Medicine Oral Pathology Oral Radiology Endodontics, Vol.103, Suppl. S25, e1-12, 2007.

[3] M.H. Thornhill, M.N. Pemberton, R.K. Simmons, E.D. Theaker. Amalgam-contact hypersensitivity lesions and oral lichen planus. Oral Surgery Oral Medicine Oral Pathology Oral Radiology Endodontics, Vol. 95, 291-299, 2003.

[4] S.S. Hsue, W.C. Wang, C.H. Chen, C.C. Lin, Y.K. Chen, L.M. Lin. Malignant transformation in 1458 patients with potentially malignant oral mucosal disorders: a follow-up study based in a Taiwanese hospital. Journal of Oral Pathology and Medicine, Vol. 36, 25-29, 2007.

[5] G.P. Bombeccari, G. Guzzi, M. Tettamanti, A.B. Giannì, A. Baj, F. Pallotti, F. Spadari. Oral lichen planus and malignant transformation: a longitudinal cohort study. Oral Surgery Oral Medicine Oral Pathology Oral Radiology Endodontics, Vol. 112, 328-334, 2011.

[6] P. Davari, H.H. Hsiao, N. Fazel. Mucosal lichen planus: an evidence-based treatment update. American Journal of Clinical Dermatology, Vol. 15, 181-195, 2014.

[7] A. González-García, M. Diniz-Freitas, P. Gándara-Vila, A. Blanco-Carrión, A. García-García, J. Gándara-Rey. Triamcinolone acetonide mouth rinses for treatment of erosive oral lichen planus: efficacy and risk of fungal over-infection. Oral Diseases, Vol. 12, 559-565, 2006.

[8] P. Tennis, J.M. Gelfand, K.J. Rothman. Evaluation of cancer risk related to atopic dermatitis and use of topical calcineurin inhibitors. British Journal of Dermatology, Vol. 165, 465-473, 2011.
[9] Sun, J-S. Chia, Y-F. Chang, C.P. Chiang. Serum interleukin-6 level is a useful marker in evaluating therapeutic effects of levamisole and Chinese medicinal herbs on patients with oral lichen planus. Journal of Oral Pathology and Medicine, Vol. 31, 196-203, 2002.

[10] F. Agha-Hosseini, K. Borhan-Mojabi, H-R. Monsef-Esfahani, I. Mirzaii-Dizgah, S. Etemad-Moghadam, A. Karagah. Efficacy of purslane in the treatment of oral lichen planus. Phytotherapy Research, Vol. 24, 240-244, 2010.

[11] B.L. McFarlin, M.H. Gibson, J. O'Rear, P. Harman. A national survey of herbal preparation use by nurse-midwives for labor stimulation. Review of the literature and recommendations for practice. Journal of Nursing-Midwifery, Vol. 44, 205-216, 1999.

[12] K. Bone. A Clinical Guide to Blending Liquid Herbs: Herbal Formulations for the Individual Patient. Churchill Livingstone Publishers, Missouri, 2003.

[13] H-K. Park, S. Hurwitz, S-B. Woo. Oral lichen planus: REU scoring system correlates with pain. Oral Surgery Oral Medicine Oral Pathology Oral Radiology, Vol. 114, 75-82, 2012.

[14] M. Russo, C. Spagnuolo, I. Tedesco, S. Bilotto, G.L. Russo. The flavonoid quercetin in disease prevention and therapy: Facts and fancies. Biochemical Pharmacology, Vol. 83, 6-15, 2012.

[15] A.Y. Chen, Y.C. Chen. A review of the dietary flavonoid, kaempferol on human health and cancer chemoprevention. Food Chemistry, Vol. 138, 2099-2107, 2013.

[16] N. Thosar, S. Basak, R.N. Bahadure, M. Rajurkar. Antimicrobial efficacy of five essential oils against oral pathogens: An in vitro study. European Journal of Dentistry, Vol. 7(Supplement 1), S71-S77, 2013. 